\title{
Estratégias de intervenção da Terapia Ocupacional em consonância com as transformações da assistência em Saúde Mental no Brasil
}

Daniela Tonizza de Almeida ${ }^{1}$ Érika Renata Trevisan ${ }^{2}$

\section{Introdução}

Historicamente, a assistência psiquiátrica no Brasil se organizou por meio de um modelo de atenção caracterizado por práticas assistenciais que enfatizavam a sintomatologia e se efetivavam por intermédio de longas internações em hospitais psiquiátricos, negligência e maus-tratos. Entretanto, essa realidade vem sendo transformada gradativamente. A mudança iniciou-se com o movimento de reforma psiquiátrica, no final da década de 1970, inspirada nos pressupostos teóricos e práticos do Modelo da Psiquiatria Comunitária Italiana (Amarante, 1998).

Um grande avanço neste processo foi a aprovação da Lei Paulo Delgado, em 2001, que prescreve a construção de uma rede de serviços substitutivos ao modelo manicomial que respeitasse o direito social e aumentasse o poder contratual dos usuários.

No conjunto dessas transformações, as identidades profissionais dos técnicos e a cisão entre diferentes disciplinas são permanentemente colocadas em questão. Trata-se de uma nova concepção de saúde e assistência que privilegia a prática e reordena o trabalho, valorizando o trabalho inter e transdisciplinar (Ballarin, Carvalho, 2007).

As transformações estruturais e ideológicas dessa nova concepção de tratamento em saúde mental trouxeram implícitas algumas inovações para a profissão. Neste contexto, a Terapia Ocupacional vem buscando legitimidade como área de atuação e de produção de saber. A profissão, por congregar conhecimentos interdisciplinares das áreas da saúde, educação, social e cultural, e se ocupar das necessidades e dificuldades das pessoas no cotidiano, apresenta um instrumental condizente com a assistência comunitária (Ribeiro, Oliveira, 2005).

Ao refletir sobre a Terapia Ocupacional, com base no conceito de Reabilitação Psicossocial, Benetton (2001) confirma essa afirmação ao apontar que os terapeutas ocupacionais brasileiros têm se mostrado mais arrojados que os colegas americanos e canadenses, participando ativamente dos processos de desospitalização e investimento em programas de intervenção na comunidade.

Ballarin e Carvalho (2007) ressaltam a heterogeneidade das práticas e dos recursos da Terapia Ocupacional que, apesar de compartilhados no trabalho em equipe, se mostram pontuais ao auxiliar no processo de desinstitucionalização

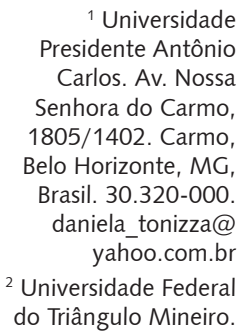

Carlos. Av, Nossa Senhora do Carmo, 1805/1402. Carmo, Belo Horizonte, MG, Brasil. 30.320-000. daniela tonizza@ Universidade Federa do Triângulo Mineiro. 
de um paciente. A partir da identificação e validação de potencialidades e interesses, da observação sistemática de seu cotidiano, do fortalecimento de vínculos e contratualidade, possibilita-se o resgate da identidade abalada com o processo de institucionalização.

Segundo Lopes e Leão (2002), como estratégia de atuação, a Terapia Ocupacional tem priorizado atendimentos grupais e, mais especificamente, as oficinas terapêuticas, pela similaridade com a proposta da profissão e priorização da atividade como uma oportunidade para a promoção de autonomia e participação social. Nesta proposta, o terapeuta ocupacional divide espaços com oficineiros, artistas e outros profissionais da saúde de forma pouco diferenciada, o que impõe a seguinte questão: essa tendência interfere na identidade e delimitação do espaço profissional?

Partindo do pressuposto de que a identidade se constitui a partir de semelhanças e diferenças, ou seja, da comparatividade com o outro, conforme Caníglia (2005), questiona-se: há possibilidade de este profissional se inserir num contexto de práticas coletivas, onde se propõe a superação do antigo paradigma da fragmentação disciplinar e, ainda assim, conservar a própria identidade?

Nessa conjuntura, surgem ainda outras indagações relativas à especificidade da profissão: de que forma o terapeuta ocupacional tem se inserido no cenário da rede de serviços substitutivos? Que ações e instrumentais ele tem utilizado para atender aos objetivos da inclusão social propostos por este novo paradigma?

\section{Metodologia}

Trata-se de uma revisão bibliográfica que pretende oferecer, ao campo interdisciplinar da Saúde Mental, um panorama geral da produção técnica e teórica da Terapia Ocupacional no período de 2002 a 2008. Para tanto, realizou-se uma busca aos artigos brasileiros relacionados ao tema, publicados em revistas científicas indexadas nas seguintes bases de dados: LILACS e SCIELO. Os artigos foram selecionados, analisados e discutidos com base nas categorias de análise: o processo da reforma psiquiátrica e a democratização da assistência; concepção de saúde; conceito de atividade, e a especificidade do terapeuta ocupacional.

Duas perspectivas teóricas, Fundamentos de Terapia Ocupacional (Caniglia, 2005) e Terapia Ocupacional em Saúde Mental (Mângia, Nicácio, 2001), ofereceram subsídios para a discussão. A Ergologia de Schwartz e Durrive (2007) também contribuiu com elementos que a enriqueceram.

\section{Resultados}

A pesquisa realizada constatou que a maior parte dos artigos publicados sobre Terapia Ocupacional no campo da Saúde Mental, no período referido, concentrava-se na Revista de Terapia Ocupacional da Universidade de São Paulo.

Nesse período, os terapeutas ocupacionais brasileiros publicaram, sobretudo, artigos que descrevem:

- as modalidades de novos serviços substitutivos (Nicácio, Campos, 2005, 2004; Mângia, Marques, 2004; Vecchi, 2004; Mângia, Rosa, 2002);

- projetos e ações interdisciplinares propostos nestes serviços (Fontes, 2008; Lima, Ghirardi, 2008; Mângia, Muramoto, 2006; Nicácio, Mângia, Ghirardi, 2005; Mângia et al., 2002);

- discussão dos fundamentos teóricos da utilização da arte como recurso terapêutico para a Terapia Ocupacional em Saúde Mental, mas que não mencionam a inserção do profissional na rede de serviços substitutivos (Castro, Silva, 2002; Lima, Pelbart, 2007; Lima, 2006a, 2006b);

- a história da Terapia Ocupacional no campo da Saúde Mental, correlacionada às concepções de saúde vigentes na sociedade e às transformações da assistência (Ribeiro, Machado, 2008; Lima, 2006a; Ribeiro, Oliveira, 2005; Oliver, Barros, Lopes, 2005);

- a Terapia Ocupacional Social que não trata especificamente da questão da saúde mental, mas inclui os sujeitos com transtorno mental em ações direcionadas a uma "população heterogênea" e a 
"grupos sociais em processos de ruptura das redes sociais de suporte". Tal inclusão parece evidenciar uma tendência à compreensão de que, independente dos sintomas ou do diagnóstico, existe uma população que está vulnerável ou excluída socialmente; e as ações da Terapia Ocupacional, segundo o paradigma da Reabilitação Psicossocial, devem propor-se a enfrentar essa condição, construindo, assim, uma interlocução entre a saúde mental e os processos sociais (Nicácio, Mângia, Ghirardi, 2005; Lima, 2003; Barros, Ghirardi, Lopes, 2002).

Dentre todas as publicações pesquisadas, três atenderam diretamente ao objetivo deste estudo, uma vez que descrevem ações específicas do terapeuta ocupacional (Ribeiro, Oliveira, 2005; Lopes, Leão, 2002) ou discutem pressupostos teóricos para a prática nos serviços substitutivos (Mângia, 2002). No entanto, mais três artigos que abordam pressupostos teóricos de terapia ocupacional relacionados à desinstitucionalização, em especial, contribuíram para ampliar a discussão (Mângia, Muramoto, 2006; Barros, Ghirardi, Lopes, 2002; Castro, Silva, 2002).

\section{Discussão}

Com base nas publicações analisadas, puderam ser observados alguns aspectos comuns. Primeiramente, a prevalência dos pressupostos da Reabilitação Psicossocial como referencial teórico, o que, de acordo com Mângia e Nicácio (2001), aponta para uma necessidade de se contextualizar a prática num cenário de transformação das instituições e de surgimento de uma nova concepção de assistência em Saúde Mental, reconhecendo as novas questões presentes nos processos de superação do modelo asilar e, ao mesmo tempo, considerando a construção de redes territoriais.

Deve-se considerar que a Reforma Psiquiátrica no Brasil ainda não está finalizada e que a Terapia Ocupacional tem contribuído com reflexões e elaboração de projetos acerca de ações e estratégias interdisciplinares para a constituição de instituições e políticas de saúde que estejam de acordo com esses novos pressupostos (Fontes, 2008; Nicácio, Mângia, Ghirardi, 2005; Nicácio, Campos, 2005, 2004; Oliver, Barros, Lopes, 2005; Mângia, Marques, 2004; Mângia, Rosa, 2002; Mângia et al., 2002). A preocupação em criar estratégias para inclusão das diversidades no contexto sociocultural orienta, de forma direta ou indireta, os discursos da assistência social, saúde e educação. Consequentemente, a Terapia Ocupacional, ao contribuir com a construção desse conhecimento, marca sua presença neste cenário de práticas interdisciplinares.

Outro aspecto, que pode ser apontado como comum, refere-se à noção de democratização da assistência, assegurando: os direitos dos usuários, a inclusão de novas tecnologias provenientes de disciplinas de outros campos de conhecimento fora da área da saúde, um maior empoderamento dos usuários nas decisões referentes ao seu projeto terapêutico e na relação com a equipe, em busca de parceria e coparticipação. Ocorreu um deslocamento da atenção dada à doença e seus sintomas para a promoção de saúde mental e inclusão social.

Referências à reformulação da concepção de saúde que orientam a prática também se mostram presentes nos artigos. Neste novo paradigma, a saúde distancia-se do conceito de ausência de doença ou de estado de completo bem-estar ou equilíbrio para a concepção de projetos de vida (Castro, Silva, 2002) que aumentam as possibilidades de trocas de recursos e afetos em uma rede de relações articuladas e flexíveis, aumentando a participação real dos sujeitos na sociedade (Saraceno, 1989 apud Mângia, Nicácio, 2001).

A Saúde Mental passa a ser compreendida como uma questão complexa que envolve fatores psicológicos, culturais, históricos, econômicos e sociais. A nova concepção de saúde que orienta a prática não se restringe à manutenção da vida, mas a viver com qualidade nos diferentes modos de vida, com criatividade (Lima, 2006a, 2006b).

A especificidade da ação do terapeuta ocupacional apresentada nos artigos pode ser avaliada a partir de dois pontos de vista: referenciais teóricos e ações. Mângia e Nicácio (2001) sugerem dois referenciais que se tornaram importantes para a Terapia Ocupacional no processo de constituição do campo da saúde mental: a Socioterapia e a Psicodinâmica. Segundo tais autoras, tais referenciais surgiram a partir da intenção de humanizar as instituições psiquiátricas, criticar o Tratamento Moral, 
a Ergoterapia, as práticas de ocupação do tempo ocioso e violações da identidade presentes nos ambientes asilares, sem, no entanto, romper com sua lógica.

Observa-se que, nas publicações analisadas neste trabalho, esses referenciais não são citados, com exceção de Ribeiro e Oliveira (2005) que cita a Psicodinâmica a partir de uma perspectiva histórica. Estima-se ainda que a escassez de publicações científicas dos referenciais Psicodinâmico, Chamoniano, Junguiano e Sistêmico, no período referido, dificulta o reconhecimento desses instrumentos como prioridades da profissão. Esta questão mostra-se como um fator limitante desse estudo, uma vez que as publicações encontradas talvez não sejam suficientes para representar a abrangência da prática do terapeuta ocupacional no contexto atual da saúde mental.

No entanto, o que se percebe é que as novas práticas destinam-se a promover o desenvolvimento de projetos não mais num setting terapêutico fechado, mas nos espaços de vida da pessoa e em atividades do cotidiano que Ihe sejam significativas, garantindo sua participação ativa no processo terapêutico.

Por intermédio da Prática Centrada no Cliente - abordagem canadense que privilegia a interação terapeuta e cliente no processo terapêutico -, rompe-se com uma prática diretiva, permitindo que o terapeuta torne-se um facilitador em tal processo. Tal abordagem propõe habilitação nas áreas de desempenho ocupacional referentes ao lazer, produtividade e autocuidado, desde que dotados de sentido para a pessoa e adequados a seu momento e contexto de vida. Verifica-se que este referencial constitui uma ferramenta de trabalho que coincide com os pressupostos da Reabilitação Psicossocial por enfatizar a coparticipação e responsabilização do usuário por seu projeto terapêutico, e por demonstrar flexibilidade quanto à utilização de modelos de intervenção diversos que atendam as demandas de cada caso (Mângia, 2002).

A noção de atividade em Terapia Ocupacional, no contexto das novas práticas, também é ressignificada, se inscrevendo nas relações entre as pessoas e os contextos, na produção de possibilidades materiais, subjetivas, sociais e culturais que viabilizem a convivência com as diferenças (Barros, Ghirardi, Lopes, 2002). As diferentes linguagens conferidas pela atividade artística também são apontadas como viabilizadoras do tratamento, ao permitirem a expressão, a comunicação e o desenvolvimento da criatividade, além da inserção sociocultural (Ribeiro, Oliveira, 2005; Castro, Silva, 2002; Lopes, Leão, 2002), assim como o engajamento em atividades produtivas de trabalho cooperado, viabilizando a participação e a contratualidade (Ribeiro, Oliveira, 2005; Lopes, Leão, 2002).

Ainda em relação às atividades, Barros, Ghirardi e Lopes (2002) consideram que a maneira como o terapeuta ocupacional as utiliza também é foco de discussão tanto em ambientes institucionais quanto extrainstitucionais. Afirmam que essas devem se constituir num meio de socialização e inter-relação, instrumento de inserção no universo do trabalho/estudo e da emancipação econômica; ser pensadas singularmente para cada pessoa, em cada situação, sempre referidas à história grupal. Abandonase, portanto, a ideia de potencial terapêutico da atividade com possibilidade de prescrição segundo patologia, sintomas ou situações hipotéticas.

Do ponto de vista das ações do terapeuta ocupacional, os relatos de experiência são poucos e abordam a questão de forma inespecífica nos textos selecionados. Lopes e Leão (2002) consideram que, no contexto de práticas coletivas que enfocam a atividade humana, o terapeuta ocupacional se diferencia pela capacidade de análise e adaptação das atividades, bem como por avaliar as relações que se estabelecem a partir delas.

Outro diferencial que especifica a atuação da Terapia Ocupacional, segundo os mesmos autores, seria a priorização dada à ação, ao processo de 'fazer', em detrimento do produto final. As autoras apontam a formação profissional como fator determinante para a valorização deste profissional nos novos equipamentos de saúde mental. Atribuem, como diferencial para a terapia ocupacional, o 'olhar', ou seja, como se compreende e intervém em cada situação (Lopes, Leão, 2002).

Essas afirmações sugerem, em suma, que o diferencial da Terapia Ocupacional não estaria no objeto de estudo - a atividade humana -, mas no processo e na forma como trabalha.

A fim de ampliar a discussão sobre a especificidade da Terapia Ocupacional, pode-se recorrer a Caniglia (2005). Esta autora propõe refletir a profissão com base no processo de trabalho. Ela afirma que, em saúde, o trabalho pressupõe uma ação no sentido de fazer com que os instrumentos atuem sobre o objeto produzindo um efeito útil. Esse efeito útil definiria a especificidade de uma profissão. 
Situa o indivíduo enquanto a matéria-prima/objeto, com uma história, uma demanda e um contexto; o profissional de saúde, enquanto um dos sujeitos produtores; os instrumentos de trabalho referem-se à metodologia, às técnicas e aos recursos terapêuticos e, finalmente, o produto seria promover, tratar ou recuperar a saúde humana.

Assim, na Terapia Ocupacional, o processo de trabalho, o raciocínio clínico e o ato terapêutico ocupacional se realizam no sentido da produção de seu objeto de trabalho, o que, no âmbito mais geral, corresponde à promoção, tratamento e recuperação da saúde humana e, num âmbito mais específico e disciplinar, do fazer humano relativo ao trabalho, lazer e atividades domésticas. Ao mesmo tempo em que busca reduzir limitações, dificuldades ou barreiras, investiga talentos, habilidades e aptidões, favorecendo o encontro entre essas habilidades e as ocupações oferecidas no mundo contemporâneo. Da mesma forma, o ato terapêutico ocupacional deve convergir ao contexto disciplinar sem limitar-se a ele, uma vez que a disciplina se alimenta da inter e da transdisciplinaridade.

Partindo desse raciocínio, o 'olhar' (Lopes, Leão, 2002) refere-se à metodologia. Sendo assim, serviria para definir a especificidade? Pode-se recorrer a uma analogia a fim de se visualizarem os termos dessa discussão: um marceneiro não se define pelo conhecimento sobre a madeira ou pela forma como serra ou martela, mas pela capacidade de produzir um objeto útil, por exemplo, uma cadeira. Ora, qualquer um que queira pode produzir uma cadeira, mas somente torna-se marceneiro quando esse ofício passa a defini-lo como pessoa, quando o produto desse trabalho se constitui em possibilidade de estabelecer trocas sociais.

Essa analogia não se verifica quando se trazem as reflexões acerca do processo de trabalho do terapeuta ocupacional para o campo da Saúde Mental. Observa-se que o produto do trabalho do terapeuta ocupacional coincide com o produto proposto pela Reabilitação Psicossocial, uma vez que autonomia e participação social se articulam com o engajamento em atividades significativas no contexto de vida (Youngstrom, 2002) e "a terapia ocupacional tem como propósito final a inclusão social" (Benetton, 2001, p.147), dificultando a definição da especificidade a partir do produto.

Portanto, com relação à especificidade do trabalho do terapeuta ocupacional no campo de transformações da assistência em Saúde Mental, o terapeuta ocupacional vive algumas contradições num contexto político que está sofrendo profundas modificações. Tal contexto propõe: descentralização, desospitalização, novos equipamentos de assistência ao portador de transtorno mental, ampliação dos recursos humanos, horizontalidade nas relações, presença de profissionais não "psi" e insuficiência da clínica psicoterapêutica. Ao mesmo tempo, a proposta de se trabalhar de forma inter e transdisciplinar coloca em questão a exclusividade das técnicas do conhecimento de cada profissional, uma vez que as intervenções passaram a ser coletivas. A formação do conhecimento e técnicas passou a ser de todos e para todos. Da mesma forma, o setting terapêutico se amplia da instituição fechada para o espaço comunitário. O trabalho aparece revitalizado, não mais como um recurso terapêutico, mas como um direito.

Dessa forma, o terapeuta ocupacional pôde verificar a valorização da atividade humana e do trabalho para a saúde mental e inserção social das pessoas e, ao mesmo tempo, se propôs a superar a ideia da atividade como recurso terapêutico ou como ocupação do tempo ocioso, presente nas práticas tradicionais. Trata-se de um momento de revisão de conceitos, o que pode causar uma sensação de estranheza com relação à identidade profissional. No entanto, este momento mostra-se crucial para contribuir com seu conhecimento sobre atividade humana para a construção do modelo teórico-assistencial interdisciplinar pautado na Reabilitação Psicossocial.

Para a reabilitação psicossocial e mais especificamente para a terapia ocupacional, o desafio da inserção social de pessoas vulneráveis e o desenvolvimento de formas de convívio com a diferença exigem transformações profundas nos modos de conceber o cuidado e organizar os serviços em confronto com as concepções e estratégias tradicionais o que implica na definição de novos perfis profissionais. (Mângia, Muramoto, 2006, p.116)

Ao analisar as mudanças que estão ocorrendo no mundo do trabalho, Schwartz e Durrive (2007) ressaltam que, cada vez que há novos princípios técnicos a serem empregados, criam-se entidades 
coletivas para operá-los de forma a sempre reconfigurá-los. Dessa forma, quando o trabalho aparecia circunscrito apenas por gestos visíveis e diferenciados por cada membro de uma equipe multidisciplinar, podiam-se definir as qualificações no coletivo de trabalho. Frequentemente, as qualificações eram restritivas tanto em relação às prescrições quanto à realidade do trabalho.

A partir do momento em que aparece a necessidade de se gerirem as interfaces técnicas e humanas no trabalho - como é o caso da Reabilitação Psicossocial -, desenvolve-se um deslizamento da qualificação para a competência, que, segundo os mesmos autores, refere-se à capacidade de gestão de todas as interfaces do trabalho, tanto técnicas quanto humanas.

Desse modo, a profissão, por apresentar um instrumental condizente com a assistência comunitária (Ribeiro, Oliveira, 2005), mostra-se qualificada. No entanto, o domínio da técnica não garante mais a inserção neste campo. Para tanto, é necessário mostrar competência no confronto cotidiano com as variabilidades e diversidades que esse contexto impõe. Nesse sentido, salienta-se a efetiva participação do terapeuta ocupacional na Reforma Psiquiátrica no Brasil, que vem compondo as novas equipes e as novas modalidades de serviços substitutivos em Saúde Mental, muitas vezes coordenando equipes ou inovando propostas de trabalho. Portanto, talvez o aspecto que aproxime seja exatamente aquele que permite a diferenciação num campo de práticas interdisciplinares. Recorrendo a analogia anterior, pode-se pensar na habilidade de se produzir uma cadeira, mas não qualquer cadeira.

Ofertas predefinidas e compartimentarizadas, de acordo com as diversas especialidades profissionais que operam com pouca ou nenhuma interação ou interatividade, resultam na concepção de um projeto terapêutico como somatória de diferentes procedimentos, desprovidos de um sentido claro para o usuário. A fim de criar processos de saber-fazer mais integrados e interativos e que, no limite, sejam capazes de superar as barreiras entre as diferentes disciplinas, Mângia e Muramoto (2006, p.118) ressaltam "a necessidade de reinventar e dotar de sentido as nossas profissionalidades e assim também, nos desinstitucionalizarmos".

\section{Considerações finais}

Observa-se que a Terapia Ocupacional, em Saúde Mental, tem se respaldado no discurso da Reabilitação Psicossocial para consolidar sua ação e inserção nos novos equipamentos da rede de serviços substitutivos. Houve uma mudança de paradigma referente aos conceitos de saúde mental no âmbito da Terapia Ocupacional, ressignificação das atividades e a ampliação do setting terapêutico, desenvolvendo ações no próprio espaço de vida dos sujeitos.

Nota-se uma tendência em abandonar um modelo de atenção centrado na doença para enfocar promoção de saúde, cidadania e participação social. O foco passa a ser a singularidade de cada indivíduo, sua história, sua cultura, seu cotidiano, em um processo que facilita o exercício da autonomia e funções na comunidade.

A Arte vem se consolidando como possibilidade de se alcançarem os objetivos tanto de expressão e comunicação, quanto de inclusão social. Trata-se da possibilidade não só de criar, mas de, a partir da manipulação de uma matéria de expressão, pensar as relações entre a criação e a produção de saúde, de enfrentamento da doença, solidão ou isolamento.

Da mesma forma, a Prática Centrada no Cliente constitui um referencial teórico específico do terapeuta ocupacional, que permite desenvolver ações em parceria com os usuários, auxiliando-os no processo de identificação de suas demandas e superação das barreiras que se interpõem à sua participação social e desempenho satisfatório nas atividades cotidianas.

Quanto à especificidade do terapeuta ocupacional, pode-se apontar que todas as ações interdisciplinares propostas pelos serviços substitutivos estão de acordo com os pressupostos teóricos que sustentam a profissão; e, ao terapeuta ocupacional, cabe o desafio de demonstrar competência no cotidiano do trabalho em equipe, pontuando o quanto sua formação e seu conhecimento sobre a atividade humana podem contribuir para alcançar os objetivos da Reabilitação Psicossocial. 
Apesar de a escassez de publicações científicas relacionadas à prática de Terapia Ocupacional em Saúde Mental no Brasil dificultar a delimitação do campo, pode sugerir que a questão da especificidade não se constitui mais no foco de estudos da profissão.

A Terapia Ocupacional tem contribuído na produção de estudos, reflexões e elaboração de projetos acerca de ações e estratégias para a constituição de instituições e políticas de saúde que estejam de acordo com os pressupostos da Reabilitação Psicossocial, superando a fragmentação disciplinar, as práticas tradicionais e definindo um novo perfil profissional. Nesse sentido, considera-se que,

Trabalhar é produzir, mas é também acumular história, constituir um patrimônio. [...] A partir do momento que alguém pode mostrar o que ele transformou em patrimônio, num lugar relativamente estável, sua participação na história toma sentido, torna-se passível de leitura. Desse ponto de vista, a história ganha consistência para ele. (Schwartz, Durrive, 2007, p.101)

\section{Colaboradores}

Daniela Tonizza de Almeida responsabilizou-se pela coleta de dados e redação; Érika Renata Trevisan pela revisão e edição final do manuscrito.

\section{Referências}

AMARANTE, P. Loucos pela vida: a trajetória da reforma psiquiátrica no Brasil. 2.ed. Rio de Janeiro: Fiocruz, 1998.

BALLARIN, M.L.G.; CARVALHO, F.B. Considerações acerca da reabilitação psicossocial: aspectos históricos, perspectivas e experiências. In: CAVALCANTE, A.; GALVÃO, C. (Orgs.). Terapia Ocupacional: fundamentação e prática. Rio de Janeiro: Guanabara Koogan, 2007. p.162-70.

BARROS, D.D.; GHIRARDI; M.I.; LOPES, R.E. Terapia Ocupacional Social. Rev. Ter. Ocup. Univ. São Paulo, v.13, n.3, p.95-103, 2002.

BENETTON, M.J. Terapia Ocupacional e Reabilitação Psicossocial: uma relação possível? In: PITTA, A. (Org.). Reabilitação psicossocial. 2.ed. São Paulo: Hucitec, 2001. p.143-9.

CANIGLIA, M. Terapia Ocupacional: um enfoque disciplinar. Belo Horizonte: Ophicina de Arte \& Prosa, 2005.

CASTRO, E.D.; SILVA, D.M. Habitando os campos da arte e da terapia ocupacional: percursos teóricos e reflexões. Rev. Ter. Ocup. Univ. São Paulo, v.13. n.1, p.1-8, 2002.

FONTES, B.A.S.M. Dos pavilhões às ruas: a âncora territorial da reforma psiquiátrica. Rev. Ter. Ocup. Univ. São Paulo, v.19, n.3, p.183-92, 2008.

LIMA, E.M.F.A. A Saúde Mental nos caminhos da Terapia Ocupacional. O Mundo da Saúde, v.30, n.1, p.117-22, 2006a.

Por uma arte menor: ressonância entre arte, clínica e loucura na contemporaneidade. Interface- Comun., Saude, Educ., v.10, n.20, p.317-29, 2006b.

Desejando a diferença: considerações acerca das relações entre terapeutas ocupacionais e as populações tradicionalmente atendidas por esses profissionais. Rev. Ter. Ocup. Univ. São Paulo, v.14, n.2, p.64-71, 2003.

LIMA, E.M.F.A.; GHIRARDI, M.I.G. Transdisciplinaridade e práticas híbridas em saúde mental. Rev. Ter. Ocup. Univ. São Paulo, v.19, n.3, p.153-8, 2008. 
LIMA, E.M.F.A.; PELBART, P.P. Arte, clínica e loucura: um território em mutação. Hist. Cienc. Saude - Manguinhos, v.14, n.3, p.709-35, 2007.

LOPES, R.E.; LEÃO, A. Terapeutas ocupacionais e os Centros de Convivência e Cooperativa: novas ações de saúde. Rev. Ter. Ocup. Univ. São Paulo, v.13, n.2, p.56-63, 2002.

MÂNGIA, E.F. Contribuições da abordagem canadense "Prática de Terapia Ocupacional Centrada no Cliente" e dos autores da desinstitucionalização italiana para a Terapia Ocupacional em Saúde Mental. Rev. Ter. Ocup. Univ. São Paulo, v.13, n.3, p.15-21, 2002.

MÂNGIA, E.F.; MARQUES, A.L.M. Desinstitucionalização e Serviços Residenciais Terapêuticos: novas perspectivas para o campo da reabilitação psicossocial. Rev. Ter. Ocup. Univ. São Paulo, v.15, n.3, p.129-35, 2004.

MÂNGIA, E.F.; MURAMOTO, M. Integralidade e construção de novas profissionalidades nos contexto dos serviços substitutivos de saúde mental. Rev. Ter. Ocup. Univ. São Paulo, v.17, n.3, p.115-22, 2006.

MÂNGIA, E.F; NICÁCIO, M.F. Terapia Ocupacional em Saúde Mental: tendências principais e desafios contemporâneos. In: DE CARLO, M.M.R.P.; BARTALOTTI, C.C. (Orgs.). Terapia Ocupacional no Brasil: fundamentos e perspectivas. São Paulo: Plexos, 2001. p.63-80.

MÂNGIA, E.F.; ROSA, C.A. Desinstitucionalização e serviços residenciais terapêuticos. Rev. Ter. Ocup. Univ. São Paulo, v.13, n.2, p.71-7, 2002.

MÂNGIA, E.F. et al. Acolhimento: uma postura, uma estratégia. Rev. Ter. Ocup. Univ. São Paulo, v.13, n.3, p.15-21, 2002.

NICÁCIO, M.F.; CAMPOS, G.W. Instituições de portas abertas: novas relações usuáriosequipes-contextos na atenção em saúde mental de base comunitária/territorial. Rev. Ter. Ocup. Univ. São Paulo, v.16, n.1, p.40-6, 2005.

A complexidade da atenção às situações de crise: contribuições da desinstitucionalização para a intervenção de praticas inovadoras em saúde mental. Rev. Ter. Ocup. Univ. São Paulo, v.15, n.2, p.71-81, 2004.

NICÁCIO, M.F.; MÂNGIA, E.F.; GHIRARDI, M.I.G. Projetos de inclusão no trabalho e emancipação de pessoas em situação de desvantagem: uma discussão de perspectivas. Rev. Ter. Ocup. Univ. São Paulo, v.16, n.2, p.62-6, 2005.

OLIVER, F.C.; BARROS, D.D.; LOPES, R.E. Estudo sobre a incorporação da terapia ocupacional no contexto das ações de saúde mental e saúde da pessoa com deficiência no Município de São Paulo entre 1989 e 1993. Rev. Ter. Ocup. Univ. São Paulo, v.16, n.1, p.31-9, 2005

RIBEIRO, M.B.S.; OLIVEIRA, L.R. Terapia Ocupacional e Saúde Mental: construindo lugares de inclusão social. Interface - Comunic., Saude, Educ., v.9, n.17, p.425-31, 2005.

RIBEIRO, M.C.; MACHADO, A.L. A Terapia Ocupacional e as novas formas do cuidar em saúde mental. Rev. Ter. Ocup. Univ. São Paulo, v.19, n.2, p.72-5, 2008.

SCHWARTZ, Y.; DURRIVE, L.; DUC, M. Técnicas e competências. In: SCHWARTZ, Y.; DURRIVE, L. (Orgs.). Trabalho e ergologia: conversas sobre atividade humana. Niterói: Ed. UFF, 2007. p.85-109.

VECHI, L.G. Serviço substitutivo em saúde mental e iatrogenia? Uma reflexão sobre a questão. Rev. Ter. Ocup. Univ. São Paulo, v.15, n.2, p.55-62, 2004.

YOUNGSTROM, M.J. Occupational Therapy practice framework: the evolution of our profissional languages. Am. J. Occup. Ther., v.56, n.6, p.609-39, 2002. 
Este estudo investigou como as mudanças que estão ocorrendo na atenção à Saúde Mental no Brasil vêm transformando a prática recente do terapeuta ocupacional, por meio de uma análise de artigos científicos publicados no período de 2002 a 2008. Considera-se que houve mudanças significativas quanto ao conceito de Saúde Mental, abandonando a assistência centrada na doença para enfocar a promoção da saúde, o resgate da cidadania e a participação social. A noção de atividade foi ressignificada e o setting terapêutico ampliou-se para o território, assim como, foram apresentados novos referenciais teóricos condizentes com a proposta de desinstitucionalização e reabilitação psicossocial. As ações interdisciplinares propostas pelos serviços substitutivos estão de acordo com os pressupostos teóricos que sustentam a profissão. Da mesma forma, o terapeuta ocupacional tem contribuído efetivamente para consolidação da Reforma Psiquiátrica Brasileira.

Palavras-chave: Terapia Ocupacional. Saúde Mental. Desinstitucionalização.

\section{Interventions strategies within Occupational Therapy consonant with the transformations in mental health care in Brazil}

This study investigated how the changes that have been taking place within mental health care in Brazil have recently been transforming occupational therapists' practices, through an analysis on scientific articles published between 2002 and 2008. It was considered that there were significant changes relating to the concept of mental health, in which diseasecentered care was abandoned in order to focus on health promotion, revival of citizenship and social participation. The idea of activity was given new meaning and the therapeutic setting was expanded to the territory. In addition, a new theoretical framework in line with proposals for deinstitutionalization and psychosocial rehabilitation was presented. The interdisciplinary actions proposed by substitutive services were in agreement with the theoretical assumptions that sustain the profession. Likewise, occupational therapists have made effective contributions towards consolidating psychiatric reform in Brazil.

Keywords: Occupational Therapy. Mental Health. Deinstitutionalization.

Estrategias de intervención de la Terapia Ocupacional de acuerdo con las transformaciones de la asistencia en Salud Mental en Brasil

Este estudio ha investigado el modo en que p los cambios que ocurren en la atención a la Salud Mental en Brasil vienen transformando la práctica reciente del terapeuta ocupacional, por medio de un análisis de artículos científicos publicados durante el periodo de 2002 a 2008. Se considera que han habido cambios significativos en relación al concepto de Salud Mental, abandonado la asistencia centrada en la enfermedad para encarar la promoción de la salud, el rescate de la ciudadanía y la participación social. La noción de actividad ha sido nuevamente significada y el setting terapéutico ampliado para el territorio, así como también se han presentado nuevos referenciales teóricos adecuados a las propuestas de evitar la institucionalización y de la rehabilitación psico-social. Las acciones interdisciplinarias propuestas por los servicios substitutivos están de acuerdo con los presupuestos teóricos que sustentan la profesión. De la misma forma, el terapeuta ocupacional ha contribuido efectivamente para la consolidación de la Reforma Psiquiátrica Brasileña.

Palabras clave: Terapia Ocupacional. Salud Mental. Desinstitucionalización. 
